\title{
Rhododendron dauricum Leaf Oil
}

National Cancer Institute

\section{Source}

National Cancer Institute. Rhododendron dauricum Leaf Oil. NCI Thesaurus. Code C107352.

The essential oil of Rhododendron dauricum. 